\title{
Cyanobacteria - An Important Candidate for Biofuels and Valuable Chemicals Production
}

\section{Kabaivanova L*}

The "Stephan Angeloff” Institute of microbiology, Bulgarian Academy of Science, Bulgaria

*Corresponding author: Kabaivanova L, The "Stephan Angeloff" Institute of microbiology, Bulgarian Academy of Science, Sofia 1113, "Acad. G. Bonchev" str 26, Bulgaria, Email: lkabaivanova@yahoo.com

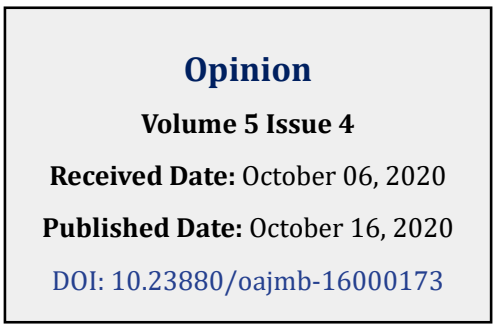

\section{Opinion}

The rapid increase in population of the world, together with the increasing demand for fossil fuelsled to an increased search for developing new technologies for use of renewable sources of energy and products. The renewable energy sources are part of the planet's physical structure. They are constantly being renewed by natural means and simply cannot run out. Biomass energy could be obtained from microorganisms and plants which is considered to be an alternative to traditional fossil fuels. Using microorganisms to produce high-value chemicals and next-generation biofuels is one sustainable approach and becomes the focus of work for many researchers.

Cyanobacteria are one of the most abundantly found organisms on earth. Cyanobacteria are aquatic and photosynthetic and they can produce their own food, in this way being an ideal platform organisms for biofuel production. In addition, they can be genetically engineered for increased synthesis of a broad range of products directly from $\mathrm{CO}_{2}, \mathrm{H}_{2} \mathrm{O}$ with the only help of sunlight, with no need of significant nutrients. Advances could be made towards improving some strains of cyanobacteria to become applicable for industrial purposes [1].

Cyanobacteria have emerged as an important platform candidate for producing biofuels and valuable chemicals due to their capability to directly utilize sunlight and $\mathrm{CO}_{2}$ as the sole energy and carbon sources. Numerous research studies have been conducted to enhance production of green fuels and chemicals through cyanobacterial modifications involving $\mathrm{CO}_{2}$ uptake and fixation, products release and cellular regulation $[2,3]$.
However, the productive potential of cyanobacteria has remained definitely unexplored. The cyanobacteria possess several advantages as organisms for creating bioindustrial processes, considering the simple input requirements, tolerance of different environments, rapid genetics, and carbon-neutral applications for obtaining alcohols, alkanes and hydrogen that could address global climate change concerns [4]. The idea of biological conversion of $\mathrm{CO}_{2}$ to fuel and chemicals deserves increased attention as direct conversion of $\mathrm{CO}_{2}$ with solar energy to biofuel by photosynthetic microorganisms such as microalgae and cyanobacteria has several advantages compared to traditional biofuel production from plant biomass. Photosynthetic microorganisms have higher growth rates compared with higher plants, and the production systems can be based on non-arable land [5,6]. The working mechanisms of these micro-organisms is the same as that of the plants, but they do not need usage of land, which could lead to crises in grain production, they live in water [7]. The needs of algae for their growth and development are easily reachable- only light, temperature, $\mathrm{N}$, and $\mathrm{P}$ have a close association with growth, development and lipid content of the microalgae. As seen, nutrient input is low. This diverse group of microorganisms is a part of marine and freshwater phytoplankton, which is assumed that had participated in the formation of earth's oil deposits. Modern cyanobacteria grow fast and efficiently convert $\mathrm{CO}_{2}$ into biomass and participate in organic chemical production. Many cyanobacterial species are easier to genetically manipulate than eukaryotic algae and other photosynthetic organisms. This is a way how the cyanobacterial photosynthesis may be directed to produce target substances such as carbohydrates, fatty acids, or 


\section{Open Access Journal of Microbiology \& Biotechnology}

alcohols as renewable sources of biofuels [8]. Exogenous metabolic pathways in these photosynthetic organisms can be routed to produce various commodity chemicals that are currently produced from petroleum. By profound studies and modifications to different components of cyanobacterial $\mathrm{CO}_{2}$-fixing systems, as well as the application of these systems toward C-derived chemical production, 2,3-butanediol is given particular focus as one of the most thoroughly studied systems for conversion of $\mathrm{CO}_{2}$ to a bioproduct [9]. Supplementation with fixed carbon sources provides additional carbon building blocks and energy to enhance production and in some cases enhanced growth. Photomixotrophic production has increased titers over traditional autotrophic conditions, demonstrating promising applications for future commercialization [10]. Alternative promising concepts are hybrid production systems of autotrophs and heterotrophs, and bio-inorganic hybrids of autotrophic microorganisms with electrocatalysts or lightharvesting semiconductor materials.

Cyanobacterial biomass can also be used for the large scale production of food, energy, biofertilizers, secondary metabolites, cosmetics and medicines. Cyanobacteria could be used as potential food additive that can ensure nutritional (rich nutrient content), therapeutic and other beneficial values [11]. Cyanobacteria are used in ecofriendly sustainable agricultural practice for production of biomass of very high value. They can act as eco-friendly biofertilizers which are easily available and less costly. They can control the nitrogen deficiency in plants, improve the aeration of soil, water holding capacity and add vitamin B12 [12]. Another possible application is their bioremediation porential [13].

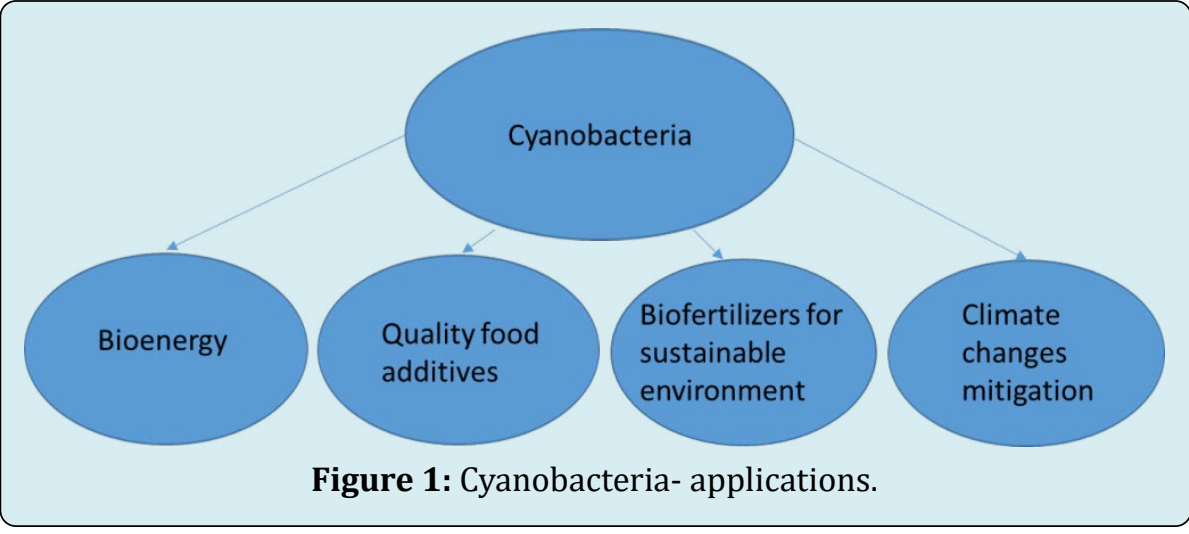

\section{Conclusion}

Cyanobacteria possess the ability to utilize $\mathrm{CO}_{2}$, water and nutrients to convert solar energy into biomass. Such autotrophic microorganisms have a large, but so far only partially realized potential for sustainable production of chemicals and biofuels. Efficient applications of cyanobacteria have been reported, including production of carbohydrates, fatty acids, or alcohols as renewable sources of biofuels, proving their impact on reducing global warming by decreasing $\mathrm{CO}_{2}$.

Acknowledgement: Thanks to BNSF: Grant KP - 06-H $26 / 5$.

\section{References}

1. Johnson TJ, Gibbons JL, Gu L, Zhou R, Gibbons WR, et al. (2016) Molecular Genetic Improvements of Cyanobacteria to Enhance the Industrial Potential of the Microbe: A Review. Biotechnol Prog 32(6): 1357-1371.

2. Zhou J, Li Y (2010) Engineering cyanobacteria for fuels and chemicals production. Protein Cell 1(3): 207-210.

3. Gao X, Sun T, Pei G, Chen L, Zhang W, et al. (2016) Cyanobacterial Chassis Engineering for Enhancing Production of Biofuels and Chemicals. Appl Microbiol Biotechnol 100(8): 3401-3413.

4. Ducat DC, Way JC, Silver PA (2011) Engineering Cyanobacteria to Generate High-Value Products. Trends Biotechnol 29(2): 95-103.

5. Machado Iara MP, Atsumi S (2012) Cyanobacterial Biofuel Production. J Biotechnol 162(1): 50-56.

6. Sarsekeyeva F, Zayadan BK, Usserbaeva A, Bedbenov VS, Sinetova MA, et al. (2015) Cyanofuels: Biofuels from Cyanobacteria. Reality and Perspectives. Photosynth Res 125(1-2): 329-340.

7. Enamalaa MK, Enamalab S, Chavalic M, Donepudid J, Yadavallie R, et al. (2018) Production of biofuels from microalgae - A review on cultivation, harvesting, lipid extraction, and numerous applications of microalgae. Renewable and Sustainable Energy Reviews 94: 49-68. 


\section{Open Access Journal of Microbiology \& Biotechnology}

8. Zhang A, Carroll AL, Atsumi S (2017) Carbon Recycling by Cyanobacteria: Improving $\mathrm{CO} 2$ Fixation through Chemical Production. FEMS Microbiol Lett 364(16).

9. Matson MM,Atsumi S (2018) Photomixotrophic Chemical Production in Cyanobacteria. Curr Opin Biotechnol 50: 65-71.

10. Claassens NJ, Sousa DZ, Dos Santos VA, de Vos WM, van der Oost J (2016) Harnessing the power of microbial autotrophy. Nat Rev Microbiol 14(11): 692-706.

11. Kedar L, Kashman Y, Oren A (2002) Mycosprine-2- glycine is the major mycosprine-like amino acid in a unicellular cyanobacterium (Euhalothece sp.) isolated from a gypsum crust in a hypersaline saltern pond. FEMS Microbiol Lett 208(2): 233-237.

12. Saadatnia H, Riahi H (2009) Cyanobacteria from paddy fields in Iran as a biofertilizer in rice plants. Plant Soil Environ 55(5): 207-212.

13. Ibraheem BM (2007) Cyanobacteria as alternative biological conditioners for bioremediation of barren soil. Egyptian J of Phycol 8: 99-117. 